\title{
Supporting Evidence from the DSM and ICD Classifications to Better Understand Traumatic Experiences, PTSD in Law
}

\author{
Yega Muthu ${ }^{1}$ \\ ${ }^{1}$ Adjunct Fellow, School of Law, Western Sydney University; Principal Solicitor, YM Lawyers, Sydney, Australia \\ Correspondence: Yega Muthu, Western Sydney University, Locked Bag 1797 Penrith NSW 2751, Australia. E- \\ mail: y.muthu@westernsydney.edu.au
}

Received: January 19, 2021

Accepted: March 5, $2021 \quad$ Online Published: March 7, 2021

doi:10.5539/jpl.v14n3p22

URL: https://doi.org/10.5539/jpl.v14n3p22

\section{Overview}

This paper will discuss the recognition of Post-Traumatic Stress Disorder (PTSD) in legal cases based on the historical development of the Diagnostic Statistical Manual for Mental Disorders (DSM). Further the discussion will draw on the diagnostic relationship between the DSM and the International Classification of Diseases (ICD). It is important to understand how the courts received evidence in relation to a person's traumatic experience and to define the limits of liability for psychiatric illness cases. In tort law, the courts had been cautious to permit recovery to underserving litigants. Interpreting traumatic experiences from psychiatry to law, at times, do not succeed in a claim for compensation. ${ }^{1}$ Belanger-Hardy opined 'Tort Law has always viewed mental harm with caution, not to say scepticism'. ${ }^{2}$ Historically, compensation for PTSD claims have always been awarded on ad hoc basis in tort law for fear of opening the floodgates. ${ }^{3}$ In Saadati v Moorhead ${ }^{4}$, Brown J acknowledged the requirement of a psychiatrist to diagnose a psychiatric disorder by referring to DSM and ICD classifications. ${ }^{5}$ The diagnostic manual is a guide book and should be used with caution. ${ }^{6}$ The DSM Manual also explains the concept of malingering and practitioners should be cautious when preparing an expert report to assist the court.

It is argued the courts are trying to play catch up with psychiatry, however, in its deliberations pronouncing inappropriate policy decisions, hampering recovery for a deserving claimant in tort law. ${ }^{7}$ Ultimately, Judges control the goal posts for awarding damages in trauma related cases. ${ }^{8}$

Historically, PTSD was defined as railway spine, shell shock, traumatic neurosis, accident neurosis and fright neurosis. Medical science established there is a relationship between the mind and body and the mind can only function in the body. Therefore, if the mind is affected by an external factor, the psyche may become muddled to develop post traumatic symptoms.

This paper will examine the method adopted by practitioners and judges in interpreting the manual. This is seen from a methodological assessment of diagnostic concordance in the light of inherent problems of psychiatric classifications and malingering. This assessment will ultimately relate to psychiatric classification of individual patients who are subjected to an intense trauma resulting in fear and helplessness. Hence, unable to relate to what had taken place and subsequently not able to realize that the psyche is muddled or disorganized. In the absence of an actual physical lesion, the courts have become sceptical and wary of extending the defendant's liability to cover

\footnotetext{
${ }^{1}$ Mulheron R, 'Rewriting the Requirement for a 'Recognised Psychiatric Injury’ in Negligence Claims' (2012) 32(1) Oxford Journal of Legal Studies $77-78$

${ }^{2}$ Belanger-Hardy L, 'Thresholds of Actionable Mental Harm in Negligence: A Policy-Based Analysis' (2013) 36 Dalhousie Law Journal 103, 104

3 Tofaris S, 'Duty of Care in Negligence: A return to orthodoxy?' (2018) The Cambridge Law Journal 454

${ }^{4}$ (2017) SCC 28

${ }^{5}$ Owen J, 'Tearing up the patchwork quilt: an examination of how, why and when liability for psychiatric injury in the tort of negligence is imposed' (2018) 10 Plymouth Law and Criminal Justice Review 1, 2

${ }^{6}$ Handford P, 'The Brave New World of Psychiatric Injury in Canada' (2018) 25 torts Law Review 136, 138

${ }^{7}$ Burrows A and Burrows J, 'A shocking requirement in the law of negligence liability for psychiatric illness: Liverpool Women's Hospital NHS Foundation Trust $v$ Ronayne

[2015] EWCA CIV 588', (2016) 24(2) Medical Law Review 278, 282

${ }^{8}$ Rix K and Cory-Wright C, 'How shocking: compensating secondary victims for psychiatric injury' (2018) 24 'BJPsych Advances 110,111
} 
alleged damage such as psychiatric illness. The inherent fears are that evidence can be confabulated and based on false premise. Hence, the courts make a linguistic interpretation in view of the struggle between the law and psychiatric illness.

Furthermore, the discussion will capture the essence of PTSD which was introduced in the 1970's and adopted in DSM-III in 1980 by the American Psychiatric Association (APA). In 1992, PTSD was recognised as a diagnosis in the International Classifications of Diseases (ICD-10) in Europe under the rubric of Neurotic, Stress-related and Somatoform Disorders by the World Health Organization (WHO). ${ }^{9}$ The DSM is a guidebook for mental health practitioners. ${ }^{10}$ However the origins of PTSD lie further back than the twentieth century. The history can be traced through the experience of the American Civil War, First World War, Second World War and the Vietnam War where veterans who returned home suffered trauma because of devastating exposure to war. Their traumatic experiences were documented and translated as symptoms which were eventually associated with PTSD, as described in DSMIII. These traumatic experiences were observed in the civil and forensic setting.

Moreover, this paper will contain a summary of the historical development of the ICD and DSM classifications depicting war associated syndromes as they played a dominant role in shaping the early diagnostic thinking of WHO and APA. From 1840 to 1921, in the United States, data was collected by gathering statistical information across mental hospitals in order to produce a nationally acceptable psychiatric nomenclature. ${ }^{11}$ In particular, a notable physician called Da Costa in the American Civil War gave the name 'irritable heart' to the symptoms suffered by some soldiers.

Consequently, the statistical information was broadened to take account of and incorporate outpatient presentations from World Wars I and II veterans. This was known as 'shell shock' and 'war neurosis'. War neurosis was further refined following World War II and the Vietnam War in terms of 'trauma'. Contemporaneously in 1948, WHO adopted the Armed Forces categorisation based on Army, Navy and Veteran experiences in World War I and II, when it integrated mental disorders into the sixth revision of the ICD depicting an European model. Mental disorders were not introduced into the ICD until its sixth edition, published by WHO in $1948,{ }^{12}$ and therefore it is not pertinent to discuss ICD classifications from 1 to 5 editions for the purposes of mental illness.

Besides, this paper will explore the development of trauma as defined in the current understanding of PTSD. This development is necessary to show how the term 'trauma' was transformed into PTSD. Evidence is also drawn from the courts as to how PTSD is used in a legal setting. As was the case for DSM-I where a category called 'gross stress reaction' ${ }^{13}$ was recognized in 1952 and a diagnosis called 'transient situational disturbance' or 'anxiety neurosis' ${ }^{14}$ was declared in DSM-II in 1968. The development of DSM-III was coordinated with the ninth revision of ICD. ${ }^{15}$ In 1980, DSM-III introduced PTSD for the first time. DSM-III made major changes in which the diagnosis of PTSD was formally introduced. DSM-III did not prescribe duration of the symptoms.

Similarly, ICD-9 did not include diagnostic criteria to specify mental categories and facilitate the collection of basic health statistics. In view of the incompatibility between ICD-9 and DSM-III, APA suggested that modifications to be made to ICD-9 for its use in the United States. The result was ICD-9-CM.

In 1987, DSM-III-R was introduced to refine the duration of symptoms.

In 1992, WHO introduced the diagnosis of PTSD in ICD-10 and consequently the APA formed a task force to develop the DSM-IV in 1994. At the time, WHO was ready to publish ICD-10. The U.S. was under a treaty to maintain systems consistent with WHO and there was a desire to build a better empirical foundation, using 13 groups of researchers in field trials. Research in natural environment diagnoses in the United States and Canada used DSM-IV, whilst most countries officially use ICD-10 and now ICD-11adopted in 2019. In DSM-IV-TR of 2002, there was still doubt by psychiatrists as to whether PTSD is an anxiety disorder or a disorder in its own category. Refinement of DSM-IV-TR was undertaken in the current DSM-5 following research.

\footnotetext{
${ }_{9}^{9}$ WHO, International Classification of Diseases and Related Health Problems, World Health Organization, Vol 1, Geneva, 1992.

${ }^{10}$ Grivas J, Oxford Psychology Study Dictionary, Oxford University Press, Melbourne, 2nd ed, 2000, 44.

${ }_{11}$ American Psychiatric Association, Diagnostic and Statistical Manual of Mental, 3rd ed, American Psychiatric Press, Washington, 1980, xvii.

${ }^{12}$ Gelder M and et al, Oxford Textbook of Psychiatry, 3rd ed, Oxford University Press, Oxford, 1996, 68.

${ }_{13}$ American Psychiatric Association, Diagnostic and Statistical Manual of Mental Disorders, 1st ed, American Psychiatric Press, Washington, 1952. This disorder denotes a reaction to a great or unusual stress that would invoke overwhelming fear in a person of normal disposition.

${ }^{14}$ American Psychiatric Association, Diagnostic and Statistical Manual of Mental Disorders, 2nd ed, American Psychiatric Press, Washington, 1968. This diagnosis denotes a person's stress response which were transient.

15 Gelder $\mathrm{M}$ et al, above n 12, 68.
} 
In addition, issues related to malingering and methodology for the detection of malingering are explored. Such methodology will confirm evidence as to whether an individual malingers or not.

In conclusion, this paper will look at the latest developments in the DSM Manual and by discussing how such a manual should be utilised effectively by the courts and psychiatrists.

\section{The Origins of Post-Traumatic Stress Disorder}

\subsection{What is PTSD?}

PTSD is defined as the development of characteristic symptoms following exposure to an extreme traumatic event. ${ }^{16}$ According to DSM-IV-TR, there are five major symptoms associated to PTSD, namely, a stressor event, re-experiencing symptoms, avoidance behaviour, numbing of general responsiveness and arousal. The individual must experience disturbance and impairment in life as a result of the exposure. ${ }^{17}$ However, in DSM-5, 'the relocation of PTSD from the anxiety disorders category to a new diagnostic category named "Trauma and Stressor related Disorders", the elimination of the subjective component to the definition of trauma, the explication and tightening of the definitions of trauma and exposure to it.'. ${ }^{18}$

Data relevant to the characteristic symptoms was predominantly derived from the American Civil War, World War I and II and the Vietnam War.

\subsection{American Civil War ${ }^{19}$}

In the American Civil War, soldiers developed symptoms of lethargy and withdrawal, exhibiting profound distress $^{20}$, timidness and weakness as a result of exposure to the war. An investigation was carried out by Civil War doctors to report on combat- related psychiatric syndromes unaccompanied by physical injury. Professor George Burr reported on symptoms suffered by certain military officers such as paralysis, loss of sensation and depersonalisation and detachment when they were in close proximity to detonating shells. ${ }^{21}$ As a result of exposure to such a catastrophic phase of the war, soldiers suffered from 'disordered action of the heart', which was comprised of cardiac sensations and indications of psychological stress. ${ }^{22}$ This was presumed to be a biological disorder that arose from physical stress. During the war, Da Costa, a visiting physician at Philadelphia Hospital, after examining more than three hundred cases, noticed a peculiar form of functional disorder of the heart, to which he gave the name 'irritable heart.' ${ }^{23}$ This was referred to variously as soldier's heart, irritable heart, effort syndrome, ${ }^{24}$ and DaCosta's syndrome. ${ }^{25}$

\subsection{Traumatic Neurosis, Shell Shock and Nervous Shock}

Advancements in medical and psychiatric knowledge during wartime facilitated the courts' understanding of 'shock' in adjudicating compensation claims. One of the earliest legal cases that demonstrated this was in Melbourne, Australia, where the court adopted psychiatric theories to propound a legally accepted model of 'nervous shock'. The Privy Council in England decided in Victorian Railways Commissioners v. James Coultas and Mary Coultas ${ }^{26}$ (Coultas) that there should be no recovery for nervous shock unaccompanied by physical injury. ${ }^{27}$ In this case, the plaintiff suffered a miscarriage due to the fright she received when the defendant's train narrowly missed the light carriage that she was on. The Privy Council's decision was made on the ground that the harm suffered was not a natural and probable consequence of the defendant's conduct. In a brief judgment, Sir

\footnotetext{
${ }^{16}$ American Psychiatric Association, Diagnostic and Statistical Manual of Mental Disorders (Text Revision), 4th ed, American Psychiatric Press, Washington, 2000, 463.

${ }^{17}$ Ibid 463 .

${ }^{18}$ Pai A et al, 'Posttraumatic Stress Disorder in the DSM-5: Controversy, Change, and Conceptual Considerations' (2017) 7 Behavioural Science 1

${ }^{19}$ Houts D, 'Posttraumatic Stress Disorder and the Legal System' in Sugarman A, Victims of Abuse: The Emotional Impact of Child and Adult Trauma, International Universities Press, Madison, 1994, 118.

${ }^{20}$ O’Brien S L, Psychiatry\&Medicine: Traumatic Events And Mental Health, 1st ed, Cambridge Press, Cambridge, 1998, 9.

${ }^{21}$ Burr G, 'Cases of Injuries of the Nervous Centres, from Explosions of Shells, without wound or Contusion' (1865) 1 New York Medical Journal $428,432$.

${ }^{22}$ Ibid 428

${ }^{23}$ Da Costa J M, 'Art.I.-On Irritable Heart; a Clinical Study of a Form of Functional Cardiac Disorder and its Consequences' (1871) 61 The American Journal of Medical Sciences 2.

${ }^{24}$ Ibid 17.

${ }^{25}$ Robitscher J B, 'The Psychiatrist and the Prisoner' in The Powers of Psychiatry, Houghton Mifflin Company, USA, 1980, 39.

${ }^{26}$ [1888] 13 AC 222.

${ }^{27}$ N Fox and F Tallis, ‘Adjustment Disorder' (1998) New Law Journal 164
} 
Richard Couch LJ made reference to the dangers of a '... wide field opened for imaginary claims. ${ }^{28}$ His Lordship spoke of an express judicial distrust of the malingering plaintiff and an implicit one of a medical charlatan who would furnish the evidence to support him or [her]. ${ }^{29}$ Recovery was disallowed because the law required psychiatric illness to be accompanied by an actual physical injury. ${ }^{30}$

Although as mentioned previously, there was medical and psychiatric advancement, such advancement was only viewed as a developing science and viewed with judicial scepticism in the light that psychiatric evidence can be faked.

Similarly, the Privy Council had the opportunity to reconsider Coultas in Bell v. Great Northern Rly Co of Ireland ${ }^{31}$. In this case, a woman suffered from fright and nervous shock when she sat in a carriage that ran uncontrollably downhill. Although she did not suffer any bodily injury, the cause of the shock was found to be the result of the defendant's negligence. She was awarded damages and the defendant appealed. The Privy Council concluded in favour of the plaintiff. Palles CB indicated the law cannot decide the connection between mind and body, it is for the expert witness to provide such testimony and draw a relationship between medicine and law. ${ }^{32}$

Palles CB's judgment is instructive. It shows an increasing acceptance of the principle that damage caused by fright should be compensable. Nevertheless, suspicion appears to remain in the judgment that psychiatric illness is not a legitimate form of illness. Certainly, in wartime, soldiers often feign symptoms associated with war neurosis and it was difficult for physicians to differentiate between the malingerer and a soldier with genuine symptoms.

The courts have a historical tradition of being most reluctant to award compensation for psychiatric illness as seen in Coultas. Over the years, however, the courts have come slowly to recognise claims for psychiatric illness as legitimate in Bell. The historical distrust for psychiatric injury, nevertheless, remains and is particularly manifest, in relation to psychiatric injuries occasioned on bystanders and those who venture upon the aftermath of an incident

\subsection{Overall Theme of World War I, II and Vietnam War}

In the First World War, Mott coined the term 'shell shock' to describe the result of environmental exposure to war. Nonetheless, Myers disagreed, on grounds that horror and fright were the main causes of such shock. There were difficulties with the label 'shell shock' and physicians were familiar with soldiers who malingered for avoiding military duties or for compensation purposes. 'Shell shock' was later eliminated because 'shell shock' was triggered by the self-preservation instinct, and subsequently substituted with the term 'war neurosis'. In World War II, the development of war neurosis in terms of 'trauma' was further refined by Kardiner, Horowitz and Abram. According to Sparr, the term 'trauma' was then extended to include severe traumatic events as exhibited in the Vietnam War.

\subsection{World War I}

During the First World War (1914-1918), a large number of soldiers became unable to fight and presented with post-traumatic symptoms mentioned previously. The exhibited symptoms were similar to those experienced in the American Civil War. Emphasis was placed upon 'shell shock' as a result of 'sudden or prolonged exposure to forces generated by high explosives. ${ }^{33}$ A neurologist, Mott, commented that at the time there was speculation that symptoms suffered were due to micro-structural lesions in the central nervous system. ${ }^{34}$

Mott coined the term 'shell shock' and suggested that the condition was due to a physical lesion of the brain, brought about in some manner by carbon monoxide or changes in atmospheric pressure. ${ }^{35}$

Mott also related shell shock to purely somatic bodily disorders and believed that the high explosives contained in huge shells could produce a direct material injury of the central nervous system. ${ }^{36}$ Moreover, Mott divided the

\footnotetext{
${ }^{28}[1888] 13$ AC 222, 226.

29 Ibid 226; A Sprince, 'Negligently inflicted psychiatric damage: a medical diagnosis and prognosis' (1998) 18 Legal Studies 59, 60. Emphasis added.

${ }^{30}$ [1888] 13 AC 222, 225.

${ }^{31}(1890) 26$ LR Ir 428.

${ }^{32} \mathrm{Ibid} 442$.

${ }^{33}$ Mott F W, 'Mental hygiene and shell shock' (1917) 2 British Medical Journal 39, 42.

${ }^{34}$ Mott F W, War Neuroses and Shell Shock, Oxford Medical Publications, London, 1919, 1,2.

${ }^{35}$ Breur J and Freud S, 'On The Physical Mechanism Of Hysterical Phenomena: Preliminary Communication (1893)' in Strachey J et al, Josef Breuer and Sigmund Freud, Hogarth Press Ltd, USA, 1955, 8.

${ }^{36}$ Mott F W, 'The Effects of High Explosives upon the Central Nervous System' (1916) The Lancet 332.
} 
effects on the central nervous system into three categories:

(a) An explosion from a building which strikes an individual, causes death or burial in an explosion; $; 7$

(b) Shock caused by other factors without physical disability; and

(c) Evidence of biological trace of 'psyche injury' may not be transparent but evidence of physical and chemical changes in the mind and body will substantiate this. ${ }^{38}$

In 1918, the APA produced a list of disorders to be used universally in mental institutions across the world. The list was only made possible through doctors across the nation treating soldiers who exhibited various kinds of disorders as a result of exposure to the war. Charles Myers, a British psychologist carried out examinations on soldiers and also analysed Mott's work.

Myers disagreed with Mott

who had experience with over 2,000 cases of shell shock divided the problem into shell concussion and shell shock. The latter gave rise to hysteria, neurasthenia, ${ }^{39}$ or even psychiatric illness, and could occur in soldiers not exposed to exploding missiles, if they were subjected to emotional stress. He concluded that the term shell shock was ill chosen and generally had little to do with carbon monoxide or atmospheric pressure but that physical causes were involved in the vast majority of cases, which were precipitated by horror and fright. ${ }^{40}$

Through relevant examination and case analysis, Myers called the disorder 'shell shock' as a direct result of exploding shells.

Although the expression 'war neurosis' was adopted and legitimised as a disease, physicians found it difficult to distinguish between neurotics and malingerers who complained of symptoms to avoid war related duties. ${ }^{41}$ This was also the case even though a physician found the presence of organic aetiology ${ }^{42}$ in a soldier who suffered 'shell shock' as a result of the trauma he experienced.

During this period, there were enormous inconsistencies amongst members of the psychological and psychiatric profession in the way they handled the complaint. Although recognizing a war neurosis as a legitimate aspect of psychiatric disability, they also labelled some soldiers who did not exhibit symptoms of the disease as malingerers. ${ }^{43}$ Psychiatrists used psychiatric technique to treat wartime soldiers, in order to return them quickly to duty at the battlefield. Soldiers who did not return to the battlefield were regarded as deserters and cowards.

Robtischer, a psychiatrist, commented that psychiatrists during World War I kept an epidemic of neurotic illness from plaguing the army by treating wartime anxieties and soldiers who avoided duties. ${ }^{44}$ Similarly, a German historian called Homberger commented that between the war period of 1914 and 1918 war neurosis and war hysteria were so widespread that they posed a problem for the German nation, a problem which was in some measure resolved through '.. an act of national self-protection [which refused] to regard war neurotics and war hysterics as sick people... As hysteria was psychogenic, it was not a disease. ${ }^{45}$

Later it was believed that war neurosis was not limited to front line troops but was also evident in soldiers never exposed to the calamities described above. It transpired that the victims' previous history consisted of neurotic problems and the removal of soldiers from front-line or undesirable situations appeared on occasions to be a therapeutic cure. ${ }^{46}$

In 1920, Dr W H R Rivers, an internationally respected physician and anthropologist was of the opinion that shell

\footnotetext{
37 Ibid 332.

${ }^{38}$ Ibid 332.

39 A condition characterized by general lassitude, irritability, lack of concentration, worry, and hypochondria. The term was introduced into psychiatry in 1869 by G. M. Beard, an American neurologist. Used by Freud to describe a fundamental disorder in mental functioning, the term was incorrectly applied to almost any psychoneurosis and has been largely abandoned.

40 Mott F W, above n 34, 10.

${ }^{41}$ Mott F W, above n 34, 10.

42 relating to or arising external exposure affecting the bodily structure.

${ }_{43}$ Mott F W, above n 34, 218-219.

${ }^{44}$ Mott F W, above n 34 .

${ }^{45}$ Homberger E F, 'Germany and Austria' in John G Howells (ed), World History of Psychiatry, Brunner/Mazel, New York, 1975, 282.

${ }^{46}$ Kardiner A, 'Traumatic Neuroses of War' in Arieti S, American Handbook of Psychiatry Volume 1, Eight Edition, Basic Books Inc Publishers, New York, 1965, 245.
} 
shock symptoms were triggered by the instinct of self-preservation. ${ }^{47}$ Shell shock was then recommended to be eliminated from the official nomenclature because many soldiers who were not exposed to the battle began to present similar symptoms and physicians had denoted such diagnosis as psychological. ${ }^{48}$ Although the terms 'shell shock' and 'war neurosis' were used interchangeably, shell shock was officially renamed 'war neurosis' as psychiatrists were able to treat the mentally impaired with psychotherapy and therefore the aetiology of a particular disorder had to be psychological rather than organic. ${ }^{49}$ This is because the diagnosis turned on each individual soldier who may possibly malinger, feign or exhibit behaviour of a coward, to escape military duties.

\subsection{World War II}

World War II marked a major watershed in the aspects of care and treatment of the mentally ill in the United States. ${ }^{50}$ Psychiatrists such as Kardiner, Horowitz and Abram commented on the aetiology of war neurosis against the background of war veterans who were exposed to the war. ${ }^{51}$

It is important to stress the vulnerability and risk factors associated with war neurosis. The level of severity of trauma is prominent in individuals who are not of normal psyche make up. Those who are prone to suffer from trauma are at a higher level of risk of developing war neurosis. ${ }^{52}$ Clinical experiments revealed that pre-existing symptoms such as previous family history of personality dysfunction appeared to be a more reliable predictor of disorder than the traumatic experience itself. In the studies conducted on war veterans, pre-military factors interact with war related circumstances in describing symptoms associated to war neurosis. Further, poor social supports, low educational status and history of pre-military diagnosis coupled with intense exposure to war, were identified as increasing a person's susceptibility to trauma..$^{53}$

Abram Kardiner, ${ }^{54}$ Professor of Psychiatry at Columbia University, commented on the traumatic syndrome or 'neurosis of war' resulting from World War II. He found, the symptoms associated with this syndrome involved fixation on events. An example of this would include a re-emergence of the event in a dream and reawaken from such a dream. Such reawakening from the dream is a direct response to heightened level of stress as experienced in the war. This was, yet, another factor associated with exposure to the war.

During the war period, Harry Abram, ${ }^{55}$ an Associate Professor of Psychiatry at the University of Virginia School of Medicine, also observed Kardiner's assessment of psychiatric diagnosis. Abram described the psychological reactions to emergency circumstances, warfare, concentration camps ${ }^{56}$ and life threatening illness as causing heightened levels of stress.

Horowit ${ }^{57}$ shared the views of Kardiner and Abram, and endeavoured to define the nature and process of stressresponse syndromes whose features included motions of outcry, denial and avoidance, and regular intrusion of remembrance of the event. The data gathered by these physicians appears to warrant uniformity in the aetiology of a particular disorder.

Young, in modern times, referred to Kardiner's work on a systematic account of the symptomatology and psychodynamics of war neurosis and referred to Freud's understanding of the brain to protect itself from an external exposure to a traumatic event. ${ }^{58}$ Kardiner, on the other hand, commented the brain can adapt itself according to

\footnotetext{
${ }^{47}$ Mendelson G, 'The Concept of Post traumatic Stress Disorder: A Review' (1987) 10 International Journal of Law and Psychiatry 45, 50.

${ }^{48}$ Report of the War Office Committee of Enquiry on Shell Shock, HSMO, London, 1922.

${ }^{49}$ Mendelson D, The Interfaces of Medicine and Law: The history of the liability for negligently caused psychiatric injury(nervous shock), $1 \mathrm{st}$ ed, Dartmouth, Aldershot, Hants, 1998.

${ }^{50}$ Grob G N, 'Origins of DSM-I: A Study in Appearance and Reality' (1991) 148 American Journal of Psychiatry 421, 427.

${ }^{51}$ Casey P and Craven C, Psychiatry and The Law, Oak Tree Press, Ireland, 1999, 117.

52 Canino G, 'The Impact of Disasters on Mental Health: Prospective and Retrospective Analyses' (1990) 19 International Journal of Mental Health 51.

${ }^{53}$ Greed B L et al, 'Risk Factors for PTSD and Other Diagnoses in a General Sample of Vietnam Veterans' (1990) 147 American Journal of Psychiatry 729,733 .

${ }^{54}$ Kardiner A, War Stress and Neurotic Illness, Hoeber, New York, 1947; Kardiner The Traumatic Neuroses of War, Hoebner, Washington DC, 1941, 141.

${ }^{55}$ Beall L S, 'Post-Traumatic Stress Disorder: A Bibliographical Essay' (1997) 34 CHOICE 917; < http://www.lib.auburn.edu> (5 March 2021) 2.

${ }^{56}$ Krystal J H, Integration and Self Healing: Affect-Trauma- Alexithymia, 1st ed, Analytic Press, New Jersey, 1993, 137.

${ }^{57}$ Horowitz M J, Stress Response Syndromes, 2nd ed, Jason Aronson Inc, New Jersey, 1976, 43.

${ }^{58}$ Kardiner A, above n 54, 141.
} 
the internal and external exposures to a stressful event. ${ }^{59}$

According to Kardiner, there was a state of confusion in the diagnostic classification process when one drew certainty to the diagnostic categories. ${ }^{60}$

Thus, the war gave psychiatrists an opportunity to develop simple but effective means of dealing with large numbers of war casualties, meanwhile, the psychiatrists' experience in handling post war veterans helped to build a classification of symptoms associated with war neurosis.

\subsection{The Vietnam War}

According to Burnstein, ${ }^{61}$ Vietnam veterans were vulnerable to incapacitation because of exposure to severe traumatic events. In the light of such incapacitation, personality change, alcohol abuse, marital breakdown and employment instability were frequent in Vietnam veterans. ${ }^{62}$

The survey carried out by the National Vietnam Veterans Readjustment Study (NVVRS) established that following a war-related incident, it was difficult for an individual to adjust back to normal civilian life. ${ }^{63}$ Opinions also differed amongst those who believed that Vietnam veterans were more susceptible to war neurosis and those of the view that all wars produce the same types of psychological trauma. Hendin commented that soldiers lack of experience who returned from the war did contribute to developing PTSD. ${ }^{64}$

Sparr commented on the contrary view associated with war neurosis against the background of men who avoided the war and the likely stories of malingering and factitious PTSD. ${ }^{65}$

Sparr explained that many war veterans who returned from Vietnam never spoke about their traumatic experiences, under the impression that no one would believe them. ${ }^{66}$ Therefore, any stress experienced would have caused a delayed psychiatric reaction. While psychiatrists were aware that there may be a motive to fabricate symptoms by the war veterans, compensation was also made available for those who could exhibit relevant symptoms. Sparr further stated:

Among those individuals manifesting delayed stress reactions are some who are simulating the disorder. Simulation is easy, since the symptoms described .... mostly reflect private phenomenology and since by definition the symptoms are caused by events now passed. Patients may manufacture or exaggerate symptoms and misidentify their origin. It is not always easy to determine if distortions are outright lies or subtle misperceptions. ${ }^{67}$

Factitious disorder is a label attributed to an individual who distorts or exaggerates symptoms. However, to avoid such a situation, factitious disorders of any type are best discovered by a careful clinical method evaluating the information supplied by the patient and then scrutinising it.

\subsection{Traumatic Neurosis in a Judicial and Clinical Context}

As mentioned previously, advancements in medical psychiatry saw a growing awareness of recognizing mental disorders, as depicted in these various world wars. Experiences drawn from these wars then formed a template for consideration in a judicial setting.

In view of the fluctuation between a diagnosis pertaining to traumatic neurosis suffered in a war and neurosis precipitated by a non-war related trauma, the law also has difficulty with defining what a traumatic neurosis and what a non-war related trauma is. Sir Frederick Lawton, in an address to the Royal Society of Medicine, provided guidance in relation to hysterical and neurotic symptoms ${ }^{68}$ explained the difficulty lies in the severity of trauma suffered by individuals in both situations.

\footnotetext{
59 Young A, The Harmony of Illusions: Inventing Post-Traumatic Stress Disorder, 1st ed, Princeton University Press, New Jersey, $1995,89$.

${ }^{60}$ Kardiner A, The Traumatic Neurosese of War, George Banta Publishing Co., Wisconsin, 1941.

${ }^{61}$ Burnstein A, 'Chronic Vietnam PTSD and Acute Civilian PTSD: A Comparison Of Treatment Experiences' (1988) 10 General Hospital Psychiatry 245,249.

${ }^{62}$ Beall L S, above n 55, 16

63 Validated by the US Congress (1983) Public Law 98-160; Kulka R A, Trauma and the Vietnam War Generation: Report of Findings From the National Vietnam Veterans Readjustment Study, Brunnel/Mazel, 1990.

${ }^{64}$ Hendin H, The Wounds of War: The Psychological Aftermath of Combat in Vietnam, Basic Books Inc Publishers, New York, 1984.

65 Sparr L, 'Factitious Post traumatic Stress Disorder' (1983) 140 American Journal of Psychiatry 1016, 1018.

66 Ibid 1018.

67 Ibid 1018.

68 Lawton F, ‘A Judicial View Of Traumatic Neurosis' (1979) 47 Medico Legal Journal 6.
} 
Accidents affect individuals in a variety of ways and more often than not people are affected psychologically. Pilowsky comments that PTSD can be overlooked if due recognition is not given to the kind of trauma suffered as some symptoms suffered by an individual are not readily transparent. ${ }^{69}$ Symptoms associated with the traumatic accident, as mentioned before, vary. Therefore Keiser, who was no doubt unhappy with the phrase 'traumatic neurosis', described symptoms such as nightmares, anxiety, and fatigue ${ }^{70}$ are similar to those related to war neurosis, where war veterans inevitably suffered mental impairment.

The importance of this lies in the victim's inability to recall frightening episodes from the accident and the possibility of the doctor who has not explored the crucial ingredients of the accident. It is suggested that in normal cases, the patient, in the light of the horrifying circumstances, can suppress crucial events. Doctors should probe to recover such repressed memory for a probable diagnosis. The doctors should also be aware of a patient who might show signs of malingering. Consequently, the patient's thoughts and feelings should be carefully articulated after the accident or event. This careful articulation of facts and circumstances will build a satisfactory appraisal of the patient's circumstances.

From this satisfactory appraisal, mental disorders were given a label and a template was created. This was subsequently included in the DSM document in the United States and ICD classifications in Europe.

\section{Diagnostic Criteria for Mental Disorders}

\subsection{Overall theme of ICD classifications}

In brief, the ICD has undergone eleven revisions to reflect advances in medical knowledge and public health. ${ }^{71}$ Whilst the ICD has achieved international recognition for its collaboration in mental health research, the mental disorder section in ICD-6 was unsatisfactory to psychiatrists in the United States. Therefore, the United States Public Health Service (USPHC), in collaboration with the APA created an alternative classificatory document called DSM-I, which was published in 1952. In the first edition of the DSM, the APA classified acute post trauma responses as stressors that occurred as a result of a traumatic event. ${ }^{72} \mathrm{~A}$ 'stressor' is defined as an exposure to a traumatic event. An individual's reaction to a trauma was psychobiological because it represented reactions of the personality to psychological, social and biological factors. In the 1960s, WHO commissioned a comprehensive review of the diagnostic issues that led to the revision of ICD-6 and 7. The revision was based on British psychiatrist Stengel's report on recent advances in diagnostic methodology. Unfortunately, the next phase of diagnostic revision, which led to DSM-II and ICD-8, did not follow Stengel's recommendation. DSM-I classification did not predict what a valid classification should be. Similarly in DSM-II, continuing reactions were recognized; , however, "transient situational disturbance" ${ }^{73}$ was used to describe an acute post-trauma response.

\subsection{ICD-6 under the Microscope}

In view of the various world wars, in 1948, WHO decided to categorize and introduce the concept of mental disorder in ICD-6. A brief history of the ICD and the DSM series is necessary to explain the development of the modern understanding of mental disorders.

The first edition of the International Classifications of Diseases (ICD) was called the International List Causes of Death. It was presented by Dr Jacques Bertillon of the International Statistical Institute in Chicago, $1893 .{ }^{74}$ The classification was then periodically revised until the fifth revision in 1938. Due to the growing number of recognized diseases suffered by people around the world, the Fifth International Revision Conference decided in 1938 to incorporate a list that would accommodate the interest of different stakeholders. ${ }^{75}$

\footnotetext{
${ }^{69}$ Pilowsky I, “Crypotrauma and “Accident Neurosis”' (1985) 147 British Journal of Psychiatry 310; Marianda M R and Kitano H H L, Mental Health Research and Practice in Minority Communities: Development of Culturally Sensitive Training Programs, US Government Printing Office, Washington,1986, xi-xiii.

${ }^{70}$ Pilowsky I, above n 69, 310.

${ }^{71}$ Gersenovic M, 'The ICD Family of Classifications' (1995) 34 Methods of Information in Medicine 172.

${ }^{72}$ Bremner J D, ‘Acute and Chronic Responses to Psychological Trauma: Where Do We Go From Here?' (1999) 156 American Journal of Psychiatry 349, 350.

${ }^{73}$ Transient Situational Disturbance is an adjustment disorder which are maladpative responses to stressful or psychologically distressing life events, such as being placed in day care for the first time, being injured in an accident, or experiencing a natural disaster. The diagnosis of an adjustment disorder requires that the inappropriate emotional or behavioural symptoms develop within three months of the stressful event or occurrence.

${ }^{74}$ Gersenovic M, above n 71, 172 .

75 Gersenovic M, above n 71, 172.
} 


\subsection{ICD-6}

In 1948, WHO, a subsidiary of the newly formed United Nations, worked on the ICD classification. ${ }^{76}$

The United States psychiatrists felt that the mental disorder component in ICD-6 was unsatisfactory. Therefore, the United States Public Health Service (USPHS) collaborated with the APA and created an alternative, the Diagnostic Statistical Manual of Mental Disorders (DSM-I), 1952. The chairperson of the APA's committee, George Raines MD, stressed the importance of the diagnostic criteria in the American Journal of Psychiatry by stating that 'accurate diagnosis is the keystone of appropriate treatment and competent prognosis. ${ }^{177}$ Whilst the United States had made an innovative move, official opinion polls for an European model, in the United Kingdom (UK) were in favour of adopting the sixth revision of the ICD. ${ }^{78}$ The sixth revision was important because it included for the first time a chapter on mental illness and acute situational maladjustment. ${ }^{79}$ Interestingly, the UK was one of the only five countries to make this move. The other countries were Finland, Peru, Thailand and New Zealand. ${ }^{80}$

At the same time in the UK, Erwin Stengel surveyed the existing classificatory systems which he called a 'Tower of Babel' ${ }^{81}$ There were important recommendations in Stengel's review which included simple but descriptive definitions of disorders in the light of widespread use of diagnostic terms with aetiological implications. Such definitions should accompany all future revisions of the ICD in a glossary form. ${ }^{82}$ Understandably, in view of the aetiological implications, the United States decided to adopt its own classification in DSM-I.

\subsection{DSM-I}

Whilst ICD-6 was adopted in Europe in 1948, DSM-I created headway for psychiatrists in the United States to categorise mental disorders based on the American society and culture. The ambits of psychological trauma have been subject to considerable fluctuation over the past two decades. ${ }^{83}$ In World Wars I and II, psychiatrists observed that soldiers often went into a state of daze, in which they did not know their identity or the environment they belonged to. Hence, psychiatrists associated this with dissociative symptoms including amnesia and depersonalisation. ${ }^{84}$ As a direct response to the compiled literature of the last world war, the APA included 'gross stress reaction' (GSR) in the first edition of DSM I, in 1952.

GSR was defined as an "acute psychological response" to stressors that occurred in an otherwise normal individual following exposure to an extreme stressor that would be traumatic for almost anyone. ${ }^{85}$ The transient nature of the disorder originates from an experience of unbearable stress. ${ }^{86}$ It was transient because if symptoms persisted, then another diagnosis needs to be substituted.

\subsection{ICD-7 to ICD-8}

In 1955, the seventh revision was confirmed in Paris to discuss essential changes and to rectify any errors or inconsistencies in ICD-6. The errors and inconsistencies were partly due to the lack of acceptance of mental disorders taxonomy. ${ }^{87}$ Ten years later, in 1965 , WHO convened a meeting in Geneva and while there was a move to change the composition of the seventh revision, any changes were left intact. This move forward was inspired by Erwin Stengel's work on a comprehensive review of classifications for mental disorders. In particular, the

${ }^{76}$ Mack A H et al, 'A Brief History of Psychiatric Classifications: From the Ancients to DSM-IV' (1994) 17 Psychiatric Clinics of North America 515, 519.

${ }^{77}$ Ibid 519.The emphasis was that the DSM was sufficiently flexible and inclusive to permit novel ideas. ICD-6 includes a component of mental diagnosis called acute situational maladjustment.

${ }^{78}$ Ibid 519.

79 Raghuram R et al, 'ICD-10 Field Trial In India-A Report: Who Sponsored Study’ (1992) 34 Indian Journal Of Psychiatry 198.

${ }^{80}$ Shepherd M, 'ICD, Mental Disorder and British Nosologists: An assessment of the uniquely British contribution to psychiatric classification' (1994) 165 British Journal of Psychiatry 1.

81 Ibid 1.

82 Ibid 2.

${ }^{83}$ Bremner J D, ‘Acute and Chronic Responses to Psychological Trauma: Where Do We Go From Here?' (1999) 156 The American Journal Of Psychiatry 349.

${ }^{84}$ Sargant W and Slater E, 'Amnesia syndromes in war' (1941) XXXIV Proceedings of the Royal Society of Medicine 757, 763,764.

${ }^{85}$ Bremner J D, above n 83, 349-350.

${ }^{86}$ Wilson J P, 'The Historical Evolution of PTSD Diagnostic Criteria: From Freud to DSM-IV' (1994) 7 Journal of Traumatic Stress 681, 689; Burchfield S R, 'The Stress Response: A New Perspective' (1979) 41 Psychosomatic Evidence 661; Prigerson H G et al, 'Consensus criteria for traumatic grief' (1999) 174 British Journal of Psychiatry 67;

${ }^{87}$ Maryama I M et al, History of the statistical Classification of Diseases and Causes of Death. Centre for Disease Control and Prevention, National Centre for Health Statistics, 2011, Chapter 3. 
general philosophy of classifying diseases according to their aetiology. Nevertheless, the next round of revision did not adopt Stengel's recommendation in ICD-8 and subsequently eliminated the term 'reaction' ${ }^{8}{ }^{8}$ The relevant period between ICD 7 and 8 saw rapid acceptance by hospitals of the indexing of medical records according to classification in many countries. ${ }^{89}$

Soon after the revelation of Stengel's report, WHO Scientific Group on Mental Health initiated an international classification of disorders to accompany ICD-8. ${ }^{90}$

The eighth revision of the ICD classification incorporated a 'transient situational disturbance' into their classification. Both ICD-8 and DSM-II went into effect in 1968. The DSM-II classification did not use the "term "reaction" and used diagnostic terms that by and large did not imply a particular theoretical framework for understanding the non-organic mental disorders. ${ }^{91}$

\subsection{DSM-II}

In DSM-II, GSR nomenclature was abandoned and reclassified as an 'adjustment reaction of adult life'. This category refers to examples of stressful life events ${ }^{92}$ that included physical threat of injury or death, or were psychologically associated with states of fear and anxiety. ${ }^{93}$ The severity, duration and proximity of an individual's exposure to the traumatic event are the most important factors affecting the likelihood of developing a disorder. Some examples include unwanted pregnancy, suicidal gestures, combat and a death sentence. ${ }^{94}$

Nevertheless, there were additional references in the appendices to describe stressful life-events. These include such things as 'motor vehicle traffic accidents, railway accidents, water transport accidents, air transport accidents and more, ad nauseam, in a highly compartmentalised and obsessive-compulsive style. ${ }^{95}$

In 1970, in the case of Mount Isa Mines Ltd v Pusey ${ }^{96}$, the High Court of Australia had an opportunity to examine a circumstance where a person may go to the aid of another person who had suffered gruesome burning injuries and suffer shock as a result of traumatic exposure to a life-threatening event.

The plaintiff was successful in this case because the employer should have foreseen that by assisting another in a gruesome manner that it was possible for the plaintiff to suffer a medically recognised form of nervous shock.

Although this case was extended to cover a person not in fear of one's safety but in fear of another, Windeyer J reiterated that, ' $[\mathrm{T}]$ he particular pathological condition which the shock produced need not have been foreseeable. It is enough that it is a recognizable psychiatric illness. ${ }^{, 97}$ Psychiatrists at the time were aware of stressful life events that may effect one's physical ability to carry on normal activities in life pursuant to the relevant diagnosis in the DSM. Walsh J quoted the judgment of Lord Macmillan in Bourhill v Young,

The crude view that the law should take cognisance only of physical injury resulting from actual impact has been discarded, and it is now well recognized that an action will lie for injury by shock sustained through the medium of the eye or the ear without direct contact. ${ }^{98}$

The recognition of trauma subsequently known as PTSD was only made possible through collation of data from field exercises.

\footnotetext{
88 American Psychiatric Association, above n 11, xxv.

89 Gersenovic M, above n 71, 172.

90 Shepherd M, 'ICD, Mental Disorder and British Nosologists: An assessment of the uniquely British contribution to psychiatric classification' (1994) 165 British Journal of Psychiatry 1, 2.

91 American Psychiatric Association, above n 11, 1-2.

92 American Psychiatric Association, Diagnostic and Statistical Manual of Mental Disorders, 4th ed, American Psychiatric Press, Washington, $1984,438$.

${ }^{93}$ Power T J and DuPaul G J, 'Implications of DSM-IV for the Practice of School Psychology: Introduction to the Mini-Series' (1996) 25 School Psychology Review 255, 256.

94 Wilson J P, above n 86, 690.

95 Birmes P et al, 'Traumatic Stress and Depression in a Group of Plane Crash Survivors' (1984); Lowenstein L F, 'Post-Traumatic Stress Reactions in Victims of Motor Accidents' (2001) 74 Police Journal 9.

96 [1970] 125 CLR 383, 413 per Windeyer J.

97 Ibid 402.

98 Ibid 415.
} 


\section{Development of Trauma as Defined in Current Understanding of PTSD}

\subsection{DSM-III and ICD-9}

In 1974, the APA began to work on the development of DSM-III, recognizing that WHO was going to publish ICD-9 in 1979. In 1980, the third edition of DSM was published and introduced the concept of PTSD.

PTSD was defined as a 'stressor event' which denotes the 'existence of a recognizable stressor that would evoke significant symptoms of distress in almost everyone. ${ }^{.99}$

DSM-III (criterion A) refined the stressor events as onset associated to PTSD. 'PTSD were external events outside the usual range' of daily routine that would be 'markedly distressing to almost everyone.' It is interesting to note that the original conception of PTSD as defined in DSM-III was based on various world wars and human and nonhuman disasters. PTSD appeared as a separate diagnosis and was accordingly placed in a separate category to anxiety disorders. This is presumably because anxiety, emotional distress and physical disequilibrium were among affective reactions associated with mental trauma. ${ }^{100}$ In United States $v$ Winters, the United States Court of Appeal, Ninth Circuit allowed the psychiatrist evidence of PTSD to corroborate the victim's account of a traumatic event. ${ }^{101}$ Similarly in State $v$ Wood $^{102}$, a Vietnam veteran who was diagnosed with PTSD when he killed his brother in law, thinking he was on a battle ground was acquitted on grounds of insanity. Whilst the Vietnam veteran was acquitted of the criminal charges, the criminal court were also mindful of the malingering with the potential misuse of PTSD diagnosis.

In DSM-III, the DSM committee abandoned the term 'neurosis' altogether. Neurosis was regarded as a novelty in psychiatric classification, primarily directed against 'the psychoanalytic etiological connotations in DSM-I and $D S M-I I .{ }^{103}$ An example of this was a diagnosis called 'transient situational disturbance' in DSM-II, where the stress response itself is transient. A category equivalent to the DSM category of PTSD is found in ICD-9 under the title of adjustment reaction.

The United States adopted the clinical modification of the ICD; full diagnosis was called 'adjustment reaction' rather than PTSD. The APA worked closely with WHO in the development of ICD-9 but felt that the glossary in ICD-9 was less than optimal and had not used recent methodological developments as specified diagnostic criteria as the United States had done. For these reasons, the APA decided to prepare a new classification that would, as much as possible, reflect the current state of knowledge whilst maintaining compatibility with ICD-9. Ultimately, a decision was made by the APA to modify ICD-9 for its use in the United States, resulting in ICD-9-CM (cm stands for 'Clinical Modification').

Initially in the DSM-III formulation, a traumatic event was conceptualised as a catastrophic stressor that was outside the range of usual human experience. ${ }^{104}$ The historical background for PTSD influenced the formulation of DSM-III. The founding committee of DSM-III had in mind 'events such as war, torture, rape, the Nazi Holocaust, the atomic bombing of Hiroshima ${ }^{105}$ and Nagasaki; natural and man-made disasters.' ${ }^{106}$ Although it was clear that there were various theories identifying how psychiatric disorders came to manifest themselves, 'the aetiology for mental disorders was still unknown. ${ }^{107}$ The APA in Washington established fourteen advisory committees consisting of experts in the important areas of mental disorders. The aim of these committees was to achieve a consensus in mental disorder classifications. ${ }^{108}$

In DSM-III, PTSD was listed as a subcategory of anxiety disorders. ${ }^{109}$ There were concerns raised by the advisory

\footnotetext{
99 American Psychiatric Association, above n 11, 236.

${ }^{100}$ Laor N et al, 'Image Control and Symptom Expression in Posttraumatic Stress Disorder' (1998) 187 Journal of Nervous and Mental Disease 673.

101729 F.2d $602\left(9^{\text {th }}\right.$ Cir.1984)

${ }^{102}$ I11 Circuit Court, 1982

${ }^{103}$ Frances A et al, 'The Classification Of Panic Disorders: From Freud to DSM-IV' (1993) 27 Journal of Psychiatric Research 3, 5.

${ }^{104}$ Friedman M J, 'Post-Traumatic Stress Disorder: An Overview'<http:www.ncptsd.org> (5 March 2021), 1.

${ }^{105}$ Lonie I, 'Borderline Disorder And Post-Traumatic Stress Disorder: An equivalence?’ (1993) 2 Australian and New Zealand Journal of Psychiatry 233, 235.

106 Friedman M J, above n 104, 1.

107 Spasser M A, 'Psychiatrists make Diagnoses, but not in circumstances of Their Own Choosing: Agency and Structure in the DSM(1)' (1998) 47 Library Trends 313.

108 Young A, above n 59, 110.

109 Beall L S, above n 55, 1.
} 
subcommittee as to whether PTSD was an anxiety or a dissociative disorder. ${ }^{110}$ Anxiety disorder was characterized by intrusive thoughts or emotions relating to an initial trauma, avoidance behaviours, and elevated arousal. ${ }^{111}$

Nevertheless, the advisory subcommittee on DSM-III unanimously classified PTSD as a new stress response category. In light of this development, PTSD was legitimised as a psychological disorder following civilian disasters and the Vietnam war. The aftermath of the Vietnam war set a template for the modern classification of PTSD. The diagnosis of post Vietnam cases was broadened to include even non-war catastrophes against the development of shell shock and war neurosis categories. Civilian catastrophes for example individuals involved in disasters such as the Coconut Grove Fire in Boston ${ }^{112}$ and the Buffalo Creek Flood in 1972,113 exhibited symptoms now associated with PTSD. These violent reactions known as PTSD were not only found in adults but noticeably in children also. For example, Newman gave an example of young children's psychological reaction to the Buffalo Creek flood. ${ }^{114}$ The emphasis of Newman's study was on emotional impairment of children under twelve years of age. ${ }^{115}$ The emotional impairment included a modified sense of reality, increased vulnerability to future stressors and altered senses of the power of the self. There are other examples which include the trauma suffered by children in a school bus hijacking which produced a lasting emotional response. ${ }^{116}$ Pathe and Mullen found evidence of substantial depression, anxiety, and other traumatic symptoms among victims of stalking in Australia. ${ }^{17}$ There was also a similarity between traumatic complaints among victims of the Boeing 737-2D6C crash in Coventry ${ }^{118}$ and stalking victims. The evidence suggests that many victims of stalking suffer from clinical or subclinical manifestations of PTSD. ${ }^{119}$

The September 11, 2001 attack by four coordinated terrorists attacks against the United States is a poignant reminder of how PTSD developed amongst directly endangered survivors; which is similar to the Oklahoma bombing experience. ${ }^{120}$ Eisen described those who developed PTSD in the September 11, 2001 tragedy as a form of 'national trauma' to better understand the traditional concept of trauma. ${ }^{121}$

Cases show that the Holocaust also had a great effect on the survivors, suffering from 'PTSD'. Clinical research has shown that the symptoms associated with their trauma often persist, even after 20 years. ${ }^{122}$

In the context of the varying range of traumatic suffering, Horowitz asserts that:

Phenomenological description of stress response syndromes has been difficult because psychological reactions always combine response keyed to a recent serious life event with previous inner models of the self and the world. ${ }^{123}$

He also notes that:

prior attitudes, conflicts, developmental arrests, personality styles, cultural premises, and networks of social support are invariably combined with recent meanings and implications. In view of past and present combinations of streams, classification has posed a problem to reflect serious life events fluctuate between diagnosis pertaining to traumatic neurosis and neurosis precipitated by trauma. ${ }^{124}$

\footnotetext{
${ }^{110}$ Richard A et al, 'Posttraumatic Stress Disorder and Psychosocial Functioning after Severe Traumatic Brain Injury' (2001) 189 The Journal of Nervous and Mental Disease 109.

111 Rauch S L et al, 'A Symptom Provocation Study of Posttraumatic Stress Disorder Using Positron Emission Tomography and Script Driven Imagery' (1996) 53 Archives of General Psychiatry 380.

112 Cobb S and Lindemann E, 'Neuropsychiatric observations after the Coconut Grove Fire' (1943) 117 Annals of Surgery 814.

${ }^{113}$ Rangell L, 'Discussion of the Buffalo Creek Disaster: The course of psychic trauma' (1976) 133 American Journal Of Psychiatry $313,316$.

114 Soloman Z, Combat Stress Reaction: The Enduring Toll of War, Plenum Press, New York, 1993, 83.

115 Newman C J, 'Children of disaster: Clinical observations at Buffalo Creek’ (1976) 133 American Journal of Psychiatry 306.

116 Terr L, 'Chowcilla revisited: The effects of psychic trauma four years after a school-bus kidnapping' (1983) 140 American Journal of Psychiatry 1543 .

117 Ibid 1543

118 Beall L S, above n 55 .

119 Kamphuis J H and Emmelkamp P M G, 'Traumatic Distress Among Support-Seeking Female Victims of Stalking' (2001) 158 American Journal of Psychiatry 795, 797.

${ }^{120}$ North C S et al, 'The post disaster prevalence of major depression relative to PTSD in survivors of the 9/11 attacks on the world trade centre selected affected workplaces' (2015) 60 Comprehensive Psychiatry 119, 122

121 Eisen J B, 'The trajectory of 'Normal' after 9/11: Trauma, Recovery and Post-Traumatic Societal Adaptation' (2002) 14 Fordham Environmental Law 499,503.

${ }^{122}$ Mendelson G, 'The concept of Post Traumatic Stress Disorder: A Review' (1987) 10 International Journal of Law and Psychiatry 45.

${ }^{123}$ Horowitz M J et al, 'Signs and Symptoms of Posttraumatic Stress Disorder' (1980) 37 Archives of General Psychiatry 85.

124 Ibid 85.
} 
In other words, each individual inflicted with such trauma experiences pain and suffering differently. Therefore, the classificatory system could not create a uniformed table of an individual's suffering, merely a general framework for suffering. ${ }^{125}$

There is a physical manifestation of trauma in PTSD that may even involve direct damage to the central nervous system. Lifton ${ }^{126}$ felt that PTSD could be construed as affecting a person of normal fortitude following abnormally stressful events. Hence, reactions and symptoms of the syndrome have a pathological impact on psychosocial functioning. The individual further experiences 'psychic numbing' or 'emotional anaesthesia' after a traumatic event. ${ }^{127}$ This may also cause the individual to avoid being reminded of the traumatic event and may cause emotional instability. ${ }^{128}$

DSM III made a powerful contribution to the growth of various signs and symptoms in medical psychiatry. Although traumatic neurosis had been inappropriately used in the past, it had never been utilized in any official psychiatric classification.

With the advent of PTSD in psychiatry and law, DSM-III had combined an understanding of the discourse between the two disciplines. When psychiatrists give evidence before a court, the evidence is filtered through in order to fit the legal paradigm, for example, the negligent infliction of psychiatric illness in the law of torts.

However in psychiatry, the framers considered traumatic events as distinctly different from the "very painful stressors that constitute the normal vicissitudes of life such as divorce, failure, rejection, serious illness, financial reverses and the like. ${ }^{129}$ In terms of DSM-III, logic dictates that an adverse psychological response to such an 'ordinary stressor' would be characterised as an adjustment disorder rather than PTSD. The dichotomy between traumatic events and other stressors is based on the assumption that most human beings have the ability to cope with ordinary stress.

It is also important to acknowledge that the words 'post traumatic', mean 'after injury'. In other words, it is an individual's state of mental and physical ability after exposure to a stressful event which is debilitating. ${ }^{130}$

In reality, after a catastrophic accident an individual may experience a wide range of abnormal responses. However, these abnormal responses are not only experienced by individuals who are present at the scene of the accident but also by individuals who may have heard of or been informed about it by the person immediately affected. ${ }^{131}$ Many reactions are associated with persons, places or things that are related to the trauma although some reactions may appear totally unrelated.

In view of the different forms of experience and involvement of an individual in the catastrophe, DSM-III added to the diagnosis for PTSD the requirement that there be "the existence of a recognisable stressor that would evoke significant symptoms of distress in almost everyone. ${ }^{132}$ This was an improvement in the diagnostic criterion, previously, neurosis or psychosis was used, and replaced with a disorder of the mind.

\subsection{Overall Theme of DSM-III-R}

In 1987, the radically revised edition of DSM-III-R was made possible as a direct result of research and clinical data collected from victims of trauma during 1980 to 1987. The result of the revision required that symptoms be present for more than one-month post trauma. ${ }^{133}$ It is a normal stress response, if the trauma experienced was for less than a month. ${ }^{134}$ Individuals who were survivors in the Buffalo Creek disaster, mentioned previously, suffered from a traumatic neurosis which lasts longer than a normal stressor. This requirement precluded inclusion

\footnotetext{
${ }^{125}$ Some commentators argued that this was a mere process of relabelling what has previously been described as 'shell shock, war neurosis, traumatic neurosis, combat trauma or combat fatigue'.

${ }^{126}$ Beall L S, above $\mathrm{n} 55,2$.

127 An individual is afraid to leave his quarters for fear of being reminded of the traumatic event.

${ }^{128}$ The Quality Assurance Project, 'Treatment Outlines For Antisocial Personality Disorder' (1991) 4 Australian and New Zealand Journal of Psychiatry 541.

${ }^{129}$ Friedman M J, above n 104, 1.

${ }^{130}$ Ehlers A et al, 'Posttraumatic Stress Disorder Following Imprisonment: The Role of Mental Defect, Alienation, and Perceived Permanent Change' (2000) 109 Journal of Abnormal Psychology 45.

${ }^{131}$ Levin P, 'The Trauma Response' (1989) David Baldwin's Trauma Information Pages $1<\mathrm{http}: / /$ www.trauma-pages.com/t-facts.htm> 5 March 2021).

${ }^{132}$ American Psychiatric Association, above n 11.

133 American Psychiatric Association, Diagnostic and Statistical Manual of Mental Disorders (Text Revision), 3rd, Washington DC, 1980.

134 Wilson J P, above n 86, 693.
} 
of acutely traumatised individuals, who were instead diagnosed with adjustment disorder. ${ }^{135}$ The additional criteria was the persistent re-experiencing of a catastrophic event in DSM-III-R.

Specific, clearly defined criteria greatly improved the reliability of clinical diagnoses and multiaxial classification. ${ }^{136}$

Wilson submits that the revision was specifically to clarify the language and meanings pertaining to reactions to trauma. ${ }^{137}$

$D S M-I I I-R$ was designed and supported by committees of the APA to confirm it is evidence based. ${ }^{138}$

In DSM-III-R, a wider breath was adopted to take account of marital or domestic breakdown, bereavement and other forms of illness that affects one's cognitive ability. This is an advancement in research from DSM-III, where, data was collated from various world war catastrophes.

In an attempt to validate and clarify the language used for PTSD $^{139}$, Neal referred to Raifman's work (a Professor of Mental Health) $)^{140}$ and complained that most researchers did not agree on the extend of the causal relationship between traumatic stressors and stress disorder syndromes in a legal framework. ${ }^{141}$

Raifman was of the opinion that practitioners rely heavily on inadequate description on particular types of traumatic stress disorder. In fostering such an attitude, the practitioner's diagnosis is based solely on the patient's account of symptoms which may be difficult to verify. ${ }^{142}$

The co-existence of other psychiatric disorders further complicate a PTSD diagnosis, notably, depression, personality disorders, pathological grief disorder, substance abuse disorders and cognitive impairment. ${ }^{143}$

\subsection{DSM-III and DSM-III-R Overlap}

The overlap between PTSD and other psychiatric disorders is evident in natural disaster cases. Some examples include the Ash Wednesday Bushfires ${ }^{144}$ in Victoria (1983). Out of seventy fire fighters who suffered from PTSD, seventy-seven percent were diagnosed with a disorder such as depression, personality disorders, pathological grief disorder, substance abuse disorders and cognitive impairment. ${ }^{145}$ According to McFarlane, the existing diagnostic criteria as in DSM-III, is a not an identical disorder suffered by patients and they need to be distinguished from emotional distress as a result of exposure to a traumatic event. ${ }^{146}$

PTSD and depressive reactions were also prevalent amongst Nicaraguan adolescents after Hurricane Mitch. Hurricane Mitch was a severe hurricane which struck Central America between October 26 and November 4, 1998. The hurricane destroyed Nicaragua and Honduras. The hurricane caused individuals to suffer PTSD and depressive reactions as defined by DSM-III due to the death of a family member, forced relocation, and thoughts of revenge. In a secondary disaster, victims may also suffer the emotional effects of recovering and identifying human remains. The psychological attitude of rescuers and medical personnel can also have a direct effect on the subsequent mental

\footnotetext{
${ }_{135}$ Adjustment Disorder is defined as a debilitating reaction, usually lasting less than six months, to a stressful event or situation. It is not the same thing as post-traumatic stress disorder (PTSD), which usually occurs in reaction to a life-threatening event and can be longer lasting.

${ }^{136}$ A person described with many dimensions.

137 Wilson J P and Raphael (eds), International Handbook of Traumatic Stress Syndromes, Plenum Press, New York, 1993, 1; Spitzer R L and Williams J B W, 'International Perspectives: Summary and Commentary' in Spitzer R L et al, International Perspectives on DSM-III, 3rd ed, American Psychiatric Press, Washington, 1983, 352.

${ }_{138}$ Reid W H et al, 'The use and reliability of psychiatric diagnosis in forensic settings' (1992) 15 Psychiatric Clinic of North America 529.

139 Ibid 529.

${ }^{140}$ Dr Raifman is a Project Director, Clinical Training Center for Mental Health and Law and is also Assistant Professor of Law and Behavioural Medicine, General Faculty at University of Virginia.

${ }^{141}$ Neal L A, 'The Pitfalls of Making a Categorical Diagnosis of Post Traumatic Stress Disorder in Personal Injury Litigation' (1994) 34 Medicine, Science and Law 117, 118; Raifman L J, 'Problems of Diagnosis and Legal Causation in Courtroom Use of Post-Traumatic Stress Disorder' (1983) 1 Behavioral Sciences and the Law 115,116; Neal L A and Rose M C, 'Factitious Post Traumatic Stress Disorder: a case report' (1995) 35 Medicine, Science and Law 352 at 353;.

142 Raifman L J, above n 141, 116.

${ }^{143}$ McFarlane A C and Papay P, 'Multiple Diagnoses of Posttraumatic Stress Disorder in Victims of a Natural Disaster' (1992) 180 Journal of Nervous and Mental Disease 498, 502; Shalev A Y, 'Posttraumatic Stress Disorder among Injured Survivors of a Terrorist Attack: Predictive Value of Early Intrusion and Avoidance Symptoms' (1992) 180 Journal of Nervous and Mental Disease 505.

${ }^{144}$ McFarlane A C, 'Possttrumatic Morbidity of a Disaster: A Study of Cases Presenting for Psychiatric Treatment' (1986) 174 Journal of Nervous and Mental Disease 4, 5.

145 Ibid 4

${ }^{146}$ Ibid 12.
} 
attitudes of survivors. ${ }^{147}$ Further examples of PTSD include battered woman syndrome. The level of violence in the battering relationship may also give rise to PTSD. From the group of disorders accompanying PTSD, 'bereavement' appears to be a prominent factor underlying the diagnosis of depression during the aftermath of learning of the death of a loved one. Therefore, it would appear to be a sound diagnosis for a major depression if the depressive episode relates to the death of a loved one.

\subsection{Legal Responses to PTSD}

Previously the law had not permitted recovery for compensation for mere grief, distress or emotional harm. ${ }^{148}$ Nevertheless, damages for the negligent infliction of 'nervous shock' were examined in the law of torts ${ }^{149}$ in McLoughlin v. O'Brien. ${ }^{150}$ In this case, the plaintiff mother was at home two miles away from the scene of the accident involving her husband and three children. She was rushed to the hospital within the hour by her neighbour and learned shortly after that her daughter had died, and she witnessed the extent of her injury. The House of Lords held that the nervous shock assumed to have been suffered by her had been the reasonably foreseeable result of the injuries to her family caused by the defendant's negligence. Their Lordships commented that policy considerations should not inhibit a decision in her favour and accordingly she was entitled to recover damages. ${ }^{151}$

Similarly, the definition of PTSD was examined by the High Court of Australia in the landmark case of Jaensch v. Coffey. ${ }^{152}$ In this case the plaintiff saw her injured husband in a combination of events that led her to suffer psychiatric illness. The High Court dealt with the definition of the 'aftermath' of an accident giving rise to a claim of nervous shock and found that it should not be restricted to the claimant being present at the actual site of the injurious event. ${ }^{153}$ The definition of such an aftermath should extend to the hospital during the period of the immediate post-accident treatment of the person physically injured by the tortfeasor. ${ }^{154}$ From this decision, it is important to note that the court was prepared to contemplate recovery where a plaintiff, so devastated by being told of an accident involving family members, that he or she was unable to attend the various scenes. This is viewed as a sensible extension of the logical progression of the law. These decisions in England and Australia were inspiring as they complemented the diagnosis of PTSD in the context of medical and psychiatric development. Although both cases did not discuss the contents of DSM-III, it does demonstrate psychiatric awareness in a legal context during 1980-1984. In particular the judgment of Brennan J in Jaensch v Coffey ${ }^{155}$ where his honour reiterated the requirements of reasonable foreseeability and the shock that causes the plaintiff to suffer a recognisable psychiatric illness. Similarly in King v Philcox ${ }^{156}$, French, Kiefel and Gageler JJ referred to cases of mental harm consisting of a 'recognised psychiatric illness' which is a narrower term defined in the legislation.

However, psychiatrists and judges should be mindful of the note of caution in DSM-III-R which reads as follows:

The clinical and scientific considerations involved in categorisation of these conditions as mental disorders may not be wholly relevant to legal judgments, for example, that take into account such issues as individual responsibility, disability determination and competency. ${ }^{157}$

Psychiatric diagnosis of a patient is carried out with the assumption that the person evaluated is honest; the reason for such evaluation is to alleviate the symptoms. ${ }^{158}$ The symptoms are predominantly subjective and therefore easily feigned. For forensic or non-forensic purposes, patients may malinger.

\footnotetext{
${ }^{147}$ Goenjian A K et al, 'Posttraumatic Stress and Depressive reactions Among Nicaraguan Adolescents After Hurricane Mitch' (2001) 158 American Journal of Psychiatry 788; Goenjian A K et al, 'Posttraumatic Stress and Depressive reactions Among Nicaraguan Adolescents After Hurricane Mitch' (2001) 158 American Journal of Psychiatry 788.

148 Benson v Lee [1972] VR 879.

${ }^{149}$ Freckelton I, 'Post-traumatic Stress Disorder: A Challenge For Public and Private Health Law' (1998) 5 Journal of Law and Medicine 252, 255.

${ }^{150}[1982] 2$ AII ER 298.

${ }^{151}$ Ibid 367.

152 [1984] 155 CLR 549.

${ }^{153}$ Mendelson D, 'The defendant's liability for negligently caused nervous shock in Australia-Qua Vadis?' (1992) 18 Melbourne University Law Review 16, 37 .

${ }^{154}$ Ibid 37. The High Court noted that, in view of today's fast and efficient ambulance services, it would be anomalous to allow recovery only to those plaintiff's who could "beat the ambulance to the scene of the accident." per Deane J (1984) ALJR 426, 462.

155 [1984] 155 CLR 566,567.

156 [2015] HCA 19

${ }^{157}$ American Psychiatric Association, above n 133; World Health Organisation, International Classification of Diseases and Related Health Problems, 3rd ed, World Health Organisation, Geneva, 1987, xxix.

${ }^{158}$ Reid W H, 'Treating Clinicians and Expert Testimony' (1998) Journal of Practical Psychiatry and Behavioural Health 1.
} 
In Mendelson and Mendelson's view, malingering is defined as the simulation of disease. ${ }^{159}$ This is based on the facts related to the patient, presented to the appropriate tribunal, jury or judge. ${ }^{160}$

It has been argued by Sparr and Boehnlein ${ }^{161}$ that the DSM-III- $R$ Manual has been inappropriately used in a legal setting. This is because the manual is available to the client and their lawyer and there is a great deal of publicity in the media which could prompt one to malinger especially where the diagnosis for PTSD symptoms are subjective.

Even prior to the introduction of PTSD in DSM-III, Sir Frederick Lawton addressed the Royal Society of Medicine on this issue. He stated,

For most human beings the capacity for self-deception is so great that there is no need for malingering. Again, I think that there is much truth in that. Plaintiffs often convince themselves that they are suffering from various symptoms, which medically, at any rate, may have no organic basis. ${ }^{162}$

Clinicians should also be aware that the DSM diagnosis does not automatically answer forensic questions relating to competency ${ }^{163}$, disability and compensation payments. ${ }^{164}$

This is a condition not attributable to a mental disorder that may be a focus of attention or treatment. In both the $D S M$-III and DSM-III-R documents, specific reference has been made to excluding malingering from the classifications of mental disorders. In terms of malingering, the screening would involve careful psychiatric interviews in an attempt to make an appropriate diagnosis. This is necessary to eliminate possible individuals who may malinger out of desire for compensation or other deceitful purposes.

\subsection{DSM-IV, a Brief Discussion of DSM-5 and ICD-10}

As mentioned previously in $D S M$-III, it included a stressor event, "existence of a recognizable stressor that would evoke significant symptoms of distress in almost everyone.' 165 Subsequently, the revision of DSM-III took place as endorsed in $D S M-I I I-R$, the stressor criterion was expanded to include, 'A person has experienced an event that is outside the range of usual human experience and that would be markedly distressing to almost everyone. ${ }^{, 166}$ In $D S M-I I I-R$, the term distress, included 'exposure to actual or threatened death or injury'. This term 'death' included actual or protracted death caused imprecision in diagnosis for PTSD and led to numerous debates among psychiatrists, psychologists, lawyers and other mental health professionals. In 1994, these disagreements amongst the legal and psychiatric fields were resolved in DSM-IV.

$D S M-I V$ was approved in May 1993. DSM-IV differs from DSM-III and III-R which are based on the systematic survey of empirical evidence. The APA re-evaluated existing data after detailed perusal of available literature in DSM-III. At the heart of the evaluation was a process of critical review towards achieving a consensus in validation. Data was gathered from a wide range of research sites so that the effects of population, field trials, design features, settings in domestic and international spheres that would complement the diagnosis for PTSD in DSM-IV. ${ }^{167}$

Similarly, WHO realised in the ninth revision process that some major changes had to be implemented, in terms of psychiatric nosology. This did not only include the ICD alone but a series of additional classifications which were required to solve the reliability problem in the tenth revision, which was published in 1992.

ICD-10 included acute stress disorder, post-traumatic stress disorder and enduring personality change after

\footnotetext{
159 Mendelson G and Mendelson D, 'Legal and Psychiatric Aspects of Malingering' (1993) 1 Journal of Law and Medicine 28, 33.

160 Ibid 28.

${ }^{161}$ Sparr L F and Boehnlein J K, 'Posttraumatic Stress Disorder in Tort Actions: Forensic Minefield' (1990) 18 Bulletin Academy of Psychiatry and Law 283, 296.

${ }^{162}$ Lawton F, above n 68, 6, 8.

163 American Psychiatric Association, above n 133, xxix.

164 Neal L A, 'The Pitfalls of Making a Categorical Diagnosis of Post Traumatic Stress Disorder in Personal Injury Litigation' (1994) 34 Medicine, Science and the Law 117.

165 American Psychiatric Association, above n 11.

166 American Psychiatric Association, above n 133.

167 American Psychiatric Association, Diagnostic and Statistical Manual of Mental Disorder,4th ed, Washington, 1984; Frances A, 'DSM-IV: Issues in Development' (1995) 25 Psychiatric Annals 15,19; Frances A et al, 'The Classification Of Panic Disorders: From Freud to DSM-IV' (1993) 27 Journal of Psychiatric Research 3. In DSM-IV, with its historical antecedents to war-related catastrophe's from the Civil War, World War I and especially World War II, clearly infers that the stressor must come from the environment and that the individual must react with fear. The implementation and use of the DSM Manual clearly extends well beyond the mental health system in identifying and classifying the behavioural and emotional status of adolescents, children and adults.
} 
catastrophic experience. ${ }^{168}$ However, diagnoses already included in ICD-10 were given somewhat more consideration than those that were being proposed afresh for DSM-IV. The considerations were made possible based on collated data for European countries utilising ICD-10 and the United States for DSM-IV.

According to the APA:

Those preparing ICD-10 and DSM-IV have worked more closely to coordinate their efforts, resulting in much mutual influence. ICD-10 consists of an official coding system and other related clinical and research documents and instruments. The codes and terms provided in DSM-IV are fully compatible with ICD-9-CM and ICD-10. ${ }^{169}$

For ease of reference, each disorder has a brief description of the main and associated clinical features. Chapter $\mathrm{V}$ of $I C D$ - 10 defines PTSD as follows, arises from a delayed or protracted response to a stressful event which features flashbacks, numbness, detachment, hypervigilance, anxiety, depression experienced over a period of weeks to months fluctuating intensity. ${ }^{170}$

The diagnostic guidelines indicate that for an individual to have suffered PTSD, there must be evidence that it arose within six months of a traumatic event of exceptional severity. ${ }^{171}$ A clinician may stipulate a 'probable' diagnosis if the delay between the event and the onset was longer than six months. This is if the clinical manifestations are typical and there is no alternative identification of the disorder, for example, an anxiety, obsessive-compulsive or depressive disorder. ${ }^{172}$

DSM-IV requires the sufferer to have experienced, witnessed or been confronted by a threat to physical integrity. The sufferer must have responded with intense fear, helplessness or horror. The trauma need not have been unusual, dramatic or catastrophic.

In DSM-5, the diagnostic criteria were revised, 'trauma exposure is objectively defined, and the subjective responses to trauma exposure (criterion A2) have been removed from criterion A, separating them form the trauma definition and confining them to the symptom criteria'. ${ }^{173}$ 'The DSM - 5 and ICD - 11 define the disorder differently, reflecting disagreements in the field about whether the construct of PTSD should encompass a broad array of psychological manifestations that arise after trauma or should be focused more specifically on trauma memory phenomena. ${ }^{174}$

In addition to the level of trauma suffered, PTSD in the DSM context also included varying forms of exposure to trauma suffered by individuals in different communities ${ }^{175}$ giving rise to cross cultural psychiatry. ${ }^{176}$

In view of the impact of psychiatry in law Kirby J stated in Coates $v$ Government Insurance Office of New South Wales, ${ }^{177}$ receiving catastrophic news via modern form of telecommunication like a telephone could result in a person being traumatized although not being present in zone of immediate danger where the news originated from. ${ }^{178}$

The statement reflects the changing composition of the Australian community and different cultural attitudes to the demonstration of profound grief which affords yet another reason for reconsidering this area of the law. Similar attitude had been adopted by the framers of the ICD document in the context of their culture and social attitudes.

Likewise, taking account of all the developments, 'these advances in research and the changing nature of patient populations and the social context of psychiatry have made the careful consideration of culture in psychiatric

\footnotetext{
168 Mariyama I M et al, above n 87, chapter 3.

169 Mariyama I M et al, above $\mathrm{n} 87$, chapter 3.

${ }^{170}$ Shepherd M, above n 90, 2.

171 Long P W, 'Post-Traumatic Stress Disorder: European Description' $1992<$ http:www.meantalhealth.com> (5 March 2021).

172 Ibid 1

173 Pai A et al, above n 18, 5

174 Bryant A, 'Post - traumatic stress disorder: a state - of - the - art review of evidence and challenges' (2019) 18 World Psychiatry 259

175 Mezzich J E et al, 'The Place of Culture in DSM-IV' (1999) 187 Journal of Nervous and Mental Disease 457.

${ }^{176}$ Fabrega H, 'Psychiatric Diagnosis: A Cultural Perspective' (1987) 175 Journal of Mental Disease 383, 384; Kleinman A, Rethinking Psychiatry: From Culture Category to Personal Experience, The Free Press, New York, 1988, 1,4; Littlewood R, 'From categories to contexts: A decade of the "new cross-cultural psychiatry' (1990) 156 British Journal of Psychiatry 308; Mezzich J E and Berganza C E, Culture and Psychopathology, Colombia University Press, New York, 1984.

177 (1995) 36 NSWLR 1.

${ }^{178}$ Long P W, above n 171, 10-11.
} 
diagnosis a clinical issue of compelling importance.' ${ }^{179}$

The introduction of the DSM and ICD manuals was designed to make psychiatrists aware of the influence of culture and ethnicity in a multicultural society. Similarly, psychiatrists were encouraged 'to be aware of his or her ethnocentric biases as well as attending to personal and cultural perspectives of the patient being assessed. ${ }^{180}$

In summary, the development of PTSD was derived from research and refinement on the part of the originators of the ICD and DSM. As it stands, for a PTSD diagnosis the individual must react with intense fear, helplessness or horror to a traumatic event. ${ }^{181}$

It is also suggested from a clinical research and training perspective that the DSM is to be utilised by trained individuals and not in a 'cook book' fashion, as the diagnostic criteria in the $D S M-V$ are only meant to be used as guidelines. Similar emphasis is placed on the ICD document.

A case that demonstrated this in the DSM context was State of New South Wales $v$ Seedsman ${ }^{182}$, where a Police Constable ${ }^{183}$ in charge of investigating crimes against children, suffered from PTSD as a result of exposure to the harrowing crimes committed against children. ${ }^{184}$ There was no form of counselling or therapy given by the Police Department to alleviate any stress, anxiety or depression the officer may have had. The court allowed recovery for the negligent infliction of psychiatric illness against the New South Wales Police Service. ${ }^{185}$

Spigelman CJ stated that the DSM- $I V$ is a diagnostic formulation and not a legislative formulation in terms of statutory interpretation. The cautionary statement in DSM- $I V$ confirms that it is to be used as guidelines and not in a 'cook book' fashion. ${ }^{186}$ His Honour stated that he placed reliance on the diagnosis of the experts who gave evidence before the Supreme Court, and divergence from the DSM- $I V$ was subject to cross examination by the experts. ${ }^{187}$ Similar sentiments were echoed by the New South Wales Supreme Court of Appeal in Commonwealth of Australia $v W L$ McLean ${ }^{188}$, where the court emphasised the use of the DSM Manual in a legal setting should be used in a cautionary manner, reciting the cautionary statement as explained in the DSM.

The interplay between case law, legislation and the DSM Manual was given further consideration in SRA v Wicks; Sheehan $v S R A^{189}$. In this case, the High Court of Australia considered the definition of a recognized psychiatric illness pursuant to the DSM-IV and found in favour of the two police officers who rescued victims at the site of the 2003 Waterfall derailment and subsequently developed psychiatric illness.

Most important are the fears that DSM- $I V$ may be misused or misunderstood for forensic purposes. In most instances, a clinical classification for a mental disorder may not be sufficient to establish the existence for legal purposes of 'mental disorder,' 'mental disability', 'mental disease' or 'mental defect'. The courts may consider an individual's competence, criminal responsibility or disability to determine the appropriate legal standard whether in civil or criminal cases. ${ }^{190}$

Since the DSM-IV was published in 1994, as mentioned previously, there has been an empirical advancement in treatment for psychiatric illness. As the APA has stated, new knowledge generated by research or clinical experience will undoubtedly increase the understanding and identification of new disorders and the removal of others.

$D S M-I V$, if utilised properly, can assist the legal decision maker in making a carefully evaluated judgment, supported by empirical, clinical and research literature. ${ }^{191}$

\footnotetext{
179 Mezzich J E et al, above n 175, 458.

180 Mezzich J E et al, above n 175, 459.

181 Tomb D A, 'The Phenomenology of Post-Traumatic Stress Disorder' (1994) 17 The Psychiatric Clinics of North America $237,247$.

182 [2000] NSWCA $119<$ http://www.lawlink.nsw.gov.au> (5 March 2021) 2-3.

${ }^{183}$ The plaintiff was still new to the service, and without training either as a detective or in stress management, was assigned to the Child Mistreatment Unit.

${ }^{184}$ Butler D, 'Voyages in uncertain seas with dated maps: Recent developments in liability for psychiatric injury in Australia' (2000) 9 Torts Law Journal 4, 8 .

${ }^{185}$ Muthu Y, 'Psychiatric Illness and the Law of Negligence: An Historical Review' (2000) 4 Macarthur Law Review 1, 20.

186 [2000] NSWCA 119; <http://www.lawlink.nsw.gov.au> (5 March 2021) 22-23.

187 [2000] NSWCA 119; <http://www.lawlink.nsw.gov.au> (5 March 2021) 22-23.

188 [1996] NSWCA 657; http://classic.austlii.edu.au/ (5 March 2021)

189 [2010] HCC 22

${ }^{190}$ Freckelton I, above n 149, 255.

191 Jones D R, Secondary Disaster Victims: The Emotional Effects of Recovering and Identifying Human Remains, (1985) 142 American Journal of Psychiatry 303, 304. Lowenstein L F, 'The Consequences upon Victims of Violent Crime including Domestic Violence' (1999) 67
} 


\subsection{DSM-IV-TR and beyond}

It took a period of six years from the original DSM- $I V$ in 1994, to carry out the necessary research; the result being the publication of $D S M-I V-T R .{ }^{192}$ 'When an individual who has been exposed to a traumatic event develops anxiety symptoms, reexperiencing the event, and avoidance of stimuli related to the event lasting more than four weeks, they may be suffering from this anxiety disorder. ${ }^{, 193}$ Whilst DSM-IV-TR reiterated the contents of PTSD as established by its predecessors, the ongoing research in psychiatric diagnosis and new ways of understanding the aetiological and pathophysiological mechanisms can improve the validity of present diagnoses. This progress did create a template for the new DSM-V. ${ }^{194}$

In DSM-IV-TR, the seventeen symptoms ${ }^{195}$ associated with PTSD remained unchanged. However, there are differential diagnoses for PTSD, namely, adjustment disorder, acute stress disorder, obsessive-compulsive disorder and malingering.

$D S M-I V-T R$ also states that malingering should not be 'ruled out in those situations in which financial remuneration, benefit eligibility, and forensic determinations play a role. ${ }^{196}$ Malingering has been a contested issue amongst clinicians, psychiatrists and psychologists who have struggled to grasp the concept of a patient faking symptoms in order to make a gain or profit. There is a distinction made between malingering, factitious syndromes and somatoform syndromes. ${ }^{197}$ In general, malingering and associated syndromes mean that an individual either feigns, over/down plays or avoids a syndrome. These states of malingering can be detected by raising the appropriate questions by an experienced psychiatrist. Modern brain mapping techniques can also be utilised to detect malingering.

'Malingering' ${ }^{198}$ denotes faking or dramatically exaggerating a symptom for conscious gain or wealth. This is often motivated by external incentives such as avoiding military duties, avoiding work, obtaining financial compensation, avoiding criminal prosecution or possibly obtaining drugs. Malingering should strongly be suspected in the medico-legal context where a lawyer refers a client to a clinician for examination. ${ }^{199}$

'Factitious Syndrome' on the other hand refers to feigning symptoms for a 'largely or wholly unconscious purpose. ${ }^{200}$ The characterisation consists of physical and psychological symptoms exhibiting a sick role. It is noted in the DSM text that, 'A reasonable inference, in the absence of evidence that accidental ingestion occurred, is that the individual may have taken the medication intentionally. ${ }^{201}$ Nevertheless, the existence of physical symptoms does not exclude the possibility of real physical and psychological symptoms.

In the context of malingering, it is difficult carry out a spontaneous assessment of a person who complains of anxiety, depression or pain.

In an assessment, a clinician needs to answer the following questions:

1) Is the patient's presentation of symptoms unusual in nature?

2) Does the patient exhibit a desire to achieve personal gain?

3) Even if the symptoms themselves do not exhibit a desire to achieve personal gain, why did the patient want to be diagnosed? Is it to avoid an arrest or responsibility?

\footnotetext{
Medico Legal Journal 171, 172-173; Bonanno G A, 'The Crucial Importance of Empirical Evidence in the Development of Bereavement Theory: A Reply to Archer (2001)' (2001) 127 Psychological Bulletin 561; Archer J, 'Broad and Narrow Perspectives in Grief Theory: Comment on Bonanno and Kaltman' (2001) 127 Psychological Bulletin 554, 558.

192 American Psychiatric Association, Diagnostic and Statistical Manual of Mental Disorders (Text Revision), American Psychiatric Press, Washington, 4th ed, 2000.

${ }^{193} \operatorname{Ibid} 438$.

${ }^{194}$ Kupfer D J et al, A Research Agenda for DSM-V, American Psychiatric Association, Washington, 2002; Helzer J E and Huziak J J, Defining Psychopathology in the 21 st Century: DSM-V and Beyond, American Psychiatric Association, Washington, 2002; Phillips K A et al, Advancing DSM: Dilemmas in Psychiatric Diagnosis, American Psychiatric Association, Washington, 2002.

${ }^{195}$ Mayou R A, 'Unconsciousness, amnesia and psychiatric symptoms following road traffic accident injury' (2000) 177 British Journal of Psychiatry 540, 544.

196 Mezzich J E et al, above n 175, 467.

197 Reid W H, 'Law and Psychiatry: Malingering' (2000) Journal of Psychiatric Practice 226.

198 American Psychiatric Association, above n 192,739. Malingering is labelled as V65.2

199 American Psychiatric Association, above n 192,739.

${ }^{200}$ American Psychiatric Association, above n 192,513. Factitious disorder is a classification of its in DSM-IV-TR.

201 American Psychiatric Association, above n 192, 513.
} 
4) Are the circumstances of the patient so subjective that they are difficult to corroborate?

5) Does the patient deter the examining clinician from obtaining past medical records, laboratory tests and the like? 202

These are the overriding considerations that a clinician should bear in mind while conducting an examination, that there is a possibility that the patient may distort the truth. Modern technology such as brain mapping techniques, however, can further clarify the state of mind of an individual feigning evidence. The Administrative Appeals Tribunal in Malady and Repatriation Commission ${ }^{203}$ was meticulous in its approach in trying to decide whether the applicant suffered from PTSD on a balance of probabilities by resorting to the psychiatric evidence and the Manual to elicit the subjective and objective factors.

\subsection{DSM-5}

One of the major changes from DSM-IV-TR to DSM-5, as previously discussed, is the elimination of the multi axial system. The changes in DSM-5 related to behavioural symptoms divided into 4 major clusters namely, reexperiencing, arousal, avoidance and persistent negative alternations in cognition. In Simpson and Repatriation Commission (Veterans' entitlements) ${ }^{204}$, the Administrative Appeals Tribunal, stated at [132]'Thus, if the Applicant is to be found to suffer from PTSD, I must not only be satisfied that the Applicant suffers from symptoms concordant with PTSD, but also, as noted in DSM-V, those symptoms must be found to relate back to or be associated with the traumatic event the Applicant purports to have caused his PTSD and at [133] DSM-V considers the following to be "traumatic event(s)" for the purposes of diagnosing PTSD : "Exposure to actual or threatened death, serious injury, or sexual violence". 205

\section{How to Detect Malingering?}

How does a clinician determine whether a person is malingering? Psychological and neuropsychological tests can be carried out to test the suspicion, although they should not be utilised alone in making a diagnosis of malingering. There are a few neuropsychological instruments, namely the Recognition Memory Test (RMT), with 'cutoff scores which malingering may reasonably be suspected to have been tentatively established. ${ }^{206}$ Further sophisticated complex personality and symptom assessors, for example the Minnesota Multiphasic Personal Inventory (MMPI) have validity scales which are based on wide scale population.

There are also various tests to determine deception, based on an 'actuarial' test. The most common ones utilised in the United States are the Pritchard and Hiscock Tests, and the Portland Digit Recognition Test [PRDT] all of which involve a series of tasks undertaken by the evaluee and which involve the evaluee trying to remember things. Reid comments, 'When non-malingering populations are given these and similar tests, even moderately braindamaged patients routinely answer $80 \%-95 \%$ of the questions correctly (depending on the instrument). ${ }^{207}$ Therefore, a malingerer's efforts to look amnestic or brain-damaged may appear exaggerated ${ }^{208}$; resulting in more inaccurate answers than would be expected in a truly damaged person. ${ }^{209}$

\section{Conclusion}

The current understanding of PTSD was only made possible through an understanding of trauma as described in its historical vacuum. The collected data obtained via the experiences of individuals in war and non-war related events were then utilised to form a diagnosis, for example PTSD in the DSM and ICD documents. Nonetheless, there was a need for refinement and illustration of the concept.

During this period, there was a need for the original definition of disorders, and it was not until DSM-III (1980), that such definition was clearly described by the APA. Such an achievement was only made possible through research and field trials. Data was obtained from individuals who suffered from various mental disorders. WHO on the other hand, created an international equivalent in ICD-10. Thereafter, diagnostic stress response included

\footnotetext{
${ }^{202}$ Reid W H, above n 138, 226.

203 [2009] AATA $454<$ http://classic.austlii.edu.au/> (5 March 2021)

204 [2018] AATA $343<$ http://classic.austlii.edu.au/> (4 March 2021)

${ }^{205}$ [2018] AATA $343<$ http://classic.austlii.edu.au/> (4 March 2021)

206 Reid W H, above n 138, 227.

207 Reid W H, above n 138, 227.

${ }^{208}$ Spitzer R L and Endicott, Schedule for Affective Disorders and Schizophrenia (SADS), Biometric Research, New York, 1978.

${ }^{209}$ Roger R, Structured Interview of Reported Symptoms (SIRS), Psychological Assessment Resources, Odessa, 1992; Summerfield D, 'The invention of post-traumatic stress disorder and the social usefulness of a psychiatric category' (2001) 322 British Medical Journal 95, 99; 'Letters' (2001) 322 British Medical Journal 1301.
} 
PTSD in DSM-III. This was made possible because of data collection involving signs and symptoms using interviews that focused on the emotions, cognitive function and conscious experience of an individual. ${ }^{210}$ In the light of undetermined serious life manifestations, some individuals develop stress related responses characterised by intrusive feelings, destructive ideations and numbing responsiveness. ${ }^{211}$

PTSD was not recognised as a separate disorder until 1980 in DSM-III, where it was included as a sub-category of anxiety disorder. This novel classification legitimised the recognition of PTSD.

There is an abundance of scientific literature examining the biological causes of PTSD. The marked stressful occasion, or traumatic event, can cause long-term physiological and psychological problems. This has been evident throughout the centuries. ${ }^{212}$

Taking account of the different types of exposure which constitute traumatic event; being involved in warfare, an accident, loss of a relationship and other considerations - a regimented approach to recognising such categories was put in place in the DSM Manual. Such examples of exposure to traumatic events had prompted the Task Force on Nomenclature and Statistics of the American Psychiatric Association to classify PTSD in the DSM-III ${ }^{213}$ classificatory schedule. The DSM Manual was recognisably refined and eliminated old for new categories according to contemporary changes in society. With the careful diagnosis of a patient by a clinician, much of the scepticism surrounding the disease, due to association with fictitious disorder, may be eliminated.

Further revisions included the refinement of the understanding of PTSD in DSM-III and DSM-IV. Litigation for PTSD has increased as a result of the public being aware of such a disorder. DSM-IV, published in 1994, delineates a shift away from aetiology as a basis of classification and psychiatric diagnosis. ${ }^{214}$ Although not all experts and academics agree on the definition and criteria embodied in DSM-5 ${ }^{215}$, it nevertheless, holds strong as an authoritative bible for clinicians in the western world. The variety of claims have multiplied, now encompassing litigated cases such as personal injury, rape, sexual harassment, stress at work, and child abuse. As the judicial system is increasingly exposed to a multitude of psychiatric-illness based claims, the disorder has become a forum for critical examination in a legal setting. Psychiatrists must use the standard guidelines of the DSM for the possible diagnosis of the existence of a symptom or symptoms of PTSD claimants. The judicial system will have regard to reports prepared by a clinician or other clinicians of their understanding, treatment and critical examination of the patient. The purpose of such critical examination is to facilitate orderly communication in exhibiting the claim for PTSD to lawyers and judges. The exposure to a traumatic event can magnify itself depending on the coping mechanism and resilience of each individual. ${ }^{216}$ Regardless of how the psychiatrist and judge may characterise any particular event, each victim may define the situation differently. ${ }^{217}$

There are fears from within the profession itself that patients may malinger or feign their illness. ${ }^{218}$ Various neuropsychological tests and brain mapping techniques ${ }^{219}$ are available to counter this position. ${ }^{220}$

Psychiatrists summoned as expert witnesses in civil or criminal cases, wishing to appear scientific and precise, may turn to the most recent edition of the DSM Manual, which provides unambiguous method categories for diagnosing PTSD. With the aid of the DSM, the psychiatrist is not only considered competent to make a diagnosis of the patient but also to utilise the appropriate category of the DSM. They will appear to provide 'an authoritative and unchallengeable means of diagnosing or refuting a diagnosis of PTSD. ${ }^{221}$

Psychiatrists and courts must recognise the DSM's limitation. They must be able to understand that the DSM

\footnotetext{
${ }^{210}$ Horowitz M J et al, 'Signs and Symptoms of Posttraumatic Stress Disorder' (1980) 37 Archives of General Psychiatry 85, 86.

211 Ibid 85.

${ }^{212}$ Matthew et al, Neurobiological and Clinical Consequences of Stress: From Normal Adaptation to PTSD, Raven Press, 1995.

213 American Psychiatric Association, above n 11.

${ }^{214}$ Busfield J, 'Mental Illness' in Cooter R and Pickstone J (eds), Medicine in the Twentieth Century, 1st ed, Harwood Academic Publishers, Australia, 2000, 633.

215 American Psychiatric Association, Diagnostic and Statistical Manual of Mental Disorders, American Psychiatric Press, Washington, 5th ed, 2013.

216 Vesper J H and Cohen L J, 'Litigating posttraumatic stress disorder: effects on the family' (1999) 27 Journal of Psychiatry and Law 313.

217 Turton P et al, 'Incidence, correlates and predictors of post traumatic stress disorder in the pregnancy after stillbirth' (2001) 178 British Journal of Psychiatry 556, 558.

218 Sheppard B, 'Bravery and break down: A military mystery' (2001) 286 Spectator 49

${ }^{219}$ McHugh P, 'How psychiatry lost its way. An open letter in reply to Paul McHugh' (2000) 46 International Journal of Social Psychiatry $232,233$.

220 Stuart L J in Vernon v Bosely [1997] 1 AII ER 577, 586.

${ }^{221}$ Neal L A, above n 141, 117.
} 
diagnosis does not automatically answer forensic questions such as competency, non-responsibility or compensation. ${ }^{222}$ Goreta warned practitioners to be cautious in drawing a relationship between PTSD and the offending behaviour. ${ }^{223}$ Malingering is a live issue and need to be considered when preparing a report for court. Future directions could include mandating an independent psychiatric evaluation in all civil and criminal cases to better understand the diagnostic label in the DSM. By doing so in a legal setting, the possibility of malingering could be better understood and reduced, hence, draw clarity to a given case.

To the legal mind, the DSM is viewed as an authoritative text to be applied objectively balanced, against the relevant expert evidence. However,

when a sceptical psychiatrist points out that the DSM is no more than a distillate of the prejudices and power plays of a group of aging American academics, of no interest to most Europeans and only passing relevance to some Australasians, this carries no weight. Lawyers are unimpressed by such disclaimers, for in law it is exactly the texts which are produced by the consensus of the prejudices of aging jurists which do carry the weight of authority. ${ }^{224}$

In conclusion, the DSM Manual is not codified by statute. It is a diagnostic tool as the title suggests. Caution must be used when interpreting the label against the risk of malingering and pre determining a psychiatric label. Whilst acknowledging the reservations about the use of the Manual in civil and forensic settings, as evidenced in this paper, the DSM had played a pivotal role in the receipt and challenges of receiving psychiatric evidence in the legal setting.

\section{Copyrights}

Copyright for this article is retained by the author(s), with first publication rights granted to the journal.

This is an open-access article distributed under the terms and conditions of the Creative Commons Attribution license (http://creativecommons.org/licenses/by/4.0/).

${ }^{222}$ Reid W H, 'The Insanity Defense: Bad or Mad or Both?' (2000) Journal of Psychiatric Practice 169.

${ }^{223}$ Goreta M, 'Posttraumatic stress disorder resulting from war traumas and its forensic-psychiatric meaning' (1994) 22 Journal of Psychiatry and Law 505, 506.

${ }^{224}$ Pathe M T, 'The Dangerousness of the DSM-III-R' (1993) 1 Journal of Law and Medicine 47, 48. 